\title{
Editorial
}

\section{A evolução da produção científica brasileira}

Com alegria, recebi o convite para escrever o editorial do primeiro número do ano de 2019 da Revista da Faculdade de Odontologia da Universidade de Passo Fundo (RFO-UPF). Embora seja pesquisador há mais de 20 anos e tenha escrito muitos artigos, o desafio de escrever um editorial é sempre uma grande responsabilidade, principalmente em uma revista de área específica e longe de minha área de formação, que é a Engenharia Civil. Naturalmente, o cargo de Vice-Reitor de Pesquisa e Pós-graduação da UPF faz com que eu tenha que sair da minha área de conforto e encarar esses novos desafios.

Um tema que merece a reflexão de todos os pesquisadores é a relação entre quantidade e qualidade da produção científica brasileira. Um relatório recente, apresentado pela Coordenação de Aperfeiçoamento de Pessoal de Nível Superior (Capes) e elaborado por uma consultoria internacional (Research in Brazil: a report for Capes by Clarivate Analytics), mostrou que a produção científica no Brasil vem crescendo muito nas últimas décadas. Ocupamos, hoje, a $13^{\circ}$ posição no mundo, com aproximadamente 74 mil artigos em 2017. Para se ter uma ideia desse crescimento, em 1997, havíamos publicado 11 mil trabalhos e ocupávamos a $21^{\circ}$ posição mundial. O crescimento, em 20 anos, foi de $580 \%$. Um dado curioso que merece destaque é que o crescimento do número de doutores nesse mesmo período foi de $510 \%$, mostrando que existe uma forte correlação entre o crescimento da produção científica e a formação de doutores.

No entanto, quando olhamos a posição do Brasil em relação à qualidade da produção científica, os números são mais modestos. A melhor forma para avaliar o impacto de milhares de trabalhos científicos de um país é analisar as citações. Em tese, se um artigo é bom, é citado por outros estudos, e isso gera impacto e visibilidade para a pesquisa. No entanto, as taxas de citação também dependem do campo de pesquisa e da idade de um artigo (artigos mais antigos tiveram mais tempo para coletar citações do que os mais recentes). Uma das formas de retirar esses efeitos é normalizar a contagem de citações de um artigo para a média mundial. Ou seja, a média de citações mundiais normalizada é igual à unidade, e o Brasil tem um valor de 0,86. Isso significa que ainda estamos abaixo da média mundial em relação à qualidade dos nossos artigos. Contudo, o relatório da Capes deixa claro que alguns artigos brasileiros estão no seleto grupo dos artigos mais citados do planeta (top 1\%).

Outro ponto que ficou claro no relatório da Capes é que artigos produzidos com parceiros internacionais apresentam um número maior de citações do que artigos produzidos somente por pesquisadores brasileiros. Isso mostra a importância da internacionalização para o avanço da qualidade das produções brasileiras.

$\mathrm{Na}$ UPF, o cenário é muito parecido com o brasileiro. Temos aumentado a produção de artigos científicos, frutos da política implementada nos últimos anos da ampliação da pós-graduação stricto sensu. No entanto, ainda precisamos melhorar o número de citações dos nossos artigos. Uma das formas de alcançarmos essa melhoria será por meio da internacionalização dos programas e da criação de um maior número de cursos de doutorado. 
Em 2019, o Programa de Pós-Graduação em Odontologia da UPF começa a formar os primeiros doutores. Seguindo a lógica da correlação supracitada, pode-se inferir que a demanda por publicações vai aumentar. Uma opção que esses novos doutores têm é a RFO-UPF, um periódico de qualidade e que disponibiliza os artigos em meio digital, permitindo o acesso de forma gratuita.

Dr. Antônio Thomé

Vice-Reitor de Pesquisa e Pós-Graduação Universidade de Passo Fundo 